\title{
Características do perfil e dos negócios dos microempreendedores individuais no município de Campos Novos-SC
}

\author{
Márcia Marcondes Diniz, de Freitas ${ }^{1}$ \\ Diego Gadler ${ }^{2}$ \\ Amanda Telles ${ }^{3}$
}

\begin{abstract}
Resumo: $\mathrm{O}$ aumento no número de microempreendedores individuais na economia brasileira, bem como o seu desempenho e a atenção destinada à legislação tributária no Brasil têm tornado a figura do MEI mais representativa no cenário empresarial. O presente artigo tem o objetivo de analisar as características do perfil e dos negócios dos microempreendedores individuais do município de Campos Novos-SC. Para atingir os objetivos propostos, utilizou-se de uma abordagem qualitativa e da pesquisa bibliográfica e documental. A amostra possui caráter intencional e os dados são de fontes secundárias, com base em informações do Portal do Empreendedor e da Receita Federal do Brasil. Os resultados apontam o perfil do microempreendedor individual: em sua maioria, do sexo masculino, com atividades voltadas à alvenaria. Evidenciam-se, ademais, um crescimento no número de MEI no município e uma homogeneidade na receita bruta declarada, com exceção do ano de 2018. Os microempreendedores têm grande relevância no âmbito regional, com evolução da taxa de adesão de trabalhadores informais ao programa e nível de adimplência considerável.
\end{abstract}

Palavras-chave: Empreendedorismo. Informalidade. Microempreendedor individual.

Abstract: The growing increase in the number of individual microentrepreneurs, as well as their performance in the Brazilian economy, and the attention to Brazilian tax legislation have made the MEI figure more representative in the business scenario. This article aims to analyze the characteristics of the profile and business of individual microentrepreneurs in the municipality of Campos Novos-SC. Regarding the approach, the work is characterized as qualitative. In order for the proposed objectives to be achieved, it was used bibliographical and documentary research. The research sample is of an intentional nature and the data are from primary sources, based on information in the Entrepreneur Portal and the Federal Revenue Service of Brazil. The results show that the profile of the individual microentrepreneur is mostly male and has its activities focused on masonry; there is a growing increase in the MEI in the municipality and there is a homogeneity in the average gross income declared by microentrepreneurs, with the exception of 2018. Microentrepreneurs have been of great relevance at the regional level, presenting a growth of the rate of adhesion of informal workers to the program and demonstrate relevant level of compliance.

Keywords: Entrepreneurship. Individual microentrepreneur. Informality.

\footnotetext{
${ }^{1}$ Mestre em Administração pela Universidade do Oeste de Santa Catarina. Professora da Unoesc, Campus de Joaçaba. E-mail: marcia.freitas@unoesc.edu.br.

${ }^{2}$ Mestre em Administração pela Universidade do Oeste de Santa Catarina. Professor e Diretor da Unoesc, Campus de Campos Novos. E-mail: diego.gadler@unoesc.edu.br.

${ }^{3}$ Acadêmica da $7^{a}$ fase do curso de Ciências Contábeis pela Universidade do Oeste de Santa Catarina (Unoesc). Email:amanda.telles@unoesc.edu.br.
} 


\section{Introdução}

O empreendedorismo provocou diversas mudanças nas formas de pensar e de agir de empresários, ao demonstrar a importância da gestão e renovação de um negócio, não obstante os obstáculos da globalização, do livre comércio e da alta concorrência. Segundo Custódio (2011), considerando a evolução humana, pode-se dizer que, desde os povos primitivos, o homem possuía atitudes empreendedoras. Prova disso foi a necessidade de inovar na criação de ferramentas para a caça de animais.

Sarkar (2008) diz que o empreendedor é detentor de mecanismos de mudança, com capacidade de explorar oportunidades com a mescla dos recursos disponíveis. As inovações contrabalanceiam as tendências decrescentes nas indústrias e na economia em geral. Por excelência, o empreendedorismo constitui nada mais que identificar e perseguir novas formas de associação de recursos e oportunidades do mercado.

A pequena produção familiar começou a modernizar-se acompanhando as mudanças do setor privado em massa, tornando-se, assim, concorrente de grandes empresas e alvo de olhares do fisco, devido à falta de regularização e à possível (e consequente) diminuição na arrecadação de tributos. De acordo com Corseuil, Neri e Ulyssea (2014), a informalidade no Brasil foi, em parte, minimizada pela exigência para que trabalhadores assalariados possuíssem carteira de trabalho assinada. Tal reivindicação tornou a definição de informalidade diretamente associada à posse (ou à falta) desse documento.

Entre as principais novidades da última década está o Microempreendedor Individual (MEI), figura criada em 2008, com o intuito de trazer os prestadores de serviços com baixa receita para perto dos olhos do poder público, ao qual cabe vigiar e garantir os direitos desses pequenos empresários. De acordo com a FECOMÉRCIO/SP (2018), os microempreendedores representam 27\% do Produto Interno Bruto (PIB) do Brasil, um percentual que reforça a importância desse profissional no mercado do país.

Dessa forma, o problema de pesquisa deste estudo é: quais as características do perfil e dos negócios dos microempreendedores individuais do município de Campos Novos-SC? Assim, o estudo tem o objetivo de analisar os traços do perfil e dos negócios dos microempreendedores individuais do município de Campos Novos-SC.

Para o desenvolvimento deste artigo, utilizou-se a abordagem qualitativa. Quanto aos objetivos, utilizou-se o cruzamento de dados. Além desta breve introdução, este trabalho se divide em mais quatro seções: a segunda seção apresenta a fundamentação teórica; a terceira descreve os procedimentos metodológicos; a quarta seção apresenta os resultados do estudo; a quinta, as considerações finais.

\section{Referencial teórico}

Neste artigo, trata-se dos conceitos referentes ao microempreendedor individual, sua importância para a comunidade na qual se insere, bem como os benefícios diretos do optante por essa atividade profissional. 
Empreendedorismo

Para Maximiano (2011), uma empresa tem o objetivo de fornecer produtos e serviços para atender a necessidades de pessoas ou de mercados, e, com isso, obter lucro. Para obter lucro e prosperar, o empreendedor precisa adquirir recursos, estruturar um sistema de operações e assumir um compromisso com a satisfação do cliente. Essa característica deve estar cristalina na mente do empreendedor, visto que um empreendimento sobrevive com a obtenção de lucros.

A palavra empreendedorismo origina-se do francês entrepreneur e significa "aquela pessoa que assume riscos e começa algo novo". O empreendedor caracteriza-se por planejar tudo com recursos próprios, sem o grande investimento de terceiros. No Brasil, o empreendedorismo e o empreendedor tomaram forma e força nos anos 90, fazendo frente contra a abertura econômica da população e a entrada de fornecedores estrangeiros que ditavam os preços de produtos (PORTAL DO EMPREENDEDOR, 2019).

Criar pequenas empresas duradouras e diminuir as altas taxas de mortalidade desses empreendimentos são ações que preocupam e têm recebido especial atenção do governo e de entidades de classe. Isso porque, nos últimos anos, após várias tentativas de estabilização da economia e da imposição advinda do fenômeno da globalização, grandes empresas brasileiras tiveram que procurar alternativas para aumentar a competitividade, reduzir os custos e manter-se no mercado (DORNELAS, 2001).

Segundo Maximiano (2011), no Brasil, entretanto, a probabilidade de manter um novo negócio por mais de três anos é relativamente baixa. Uma das principais razões é a falta de políticas públicas para viabilizar a consolidação desses empreendimentos. O país não apresenta um cenário muito acolhedor ao pequeno empreendedor. Há poucas linhas de crédito e a falta de financiamento, em muitos casos, impede a realização do negócio. Ademais, os juros são altos e os tributos e as obrigações trabalhistas constituem uma carga pesada para os empreendedores.

De acordo com Sarkar (2008), os traços empreendedores são mais predominantes em alguns indivíduos. Porém, o empreendedorismo pode ser promovido e frutificar. A Figura 1 demonstra a distribuição dos empreendedores na sociedade, como eles nascem, tornam-se empreendedores e podem ser influenciados. 
Esquema 1- Distribuição dos empreendedores na sociedade.

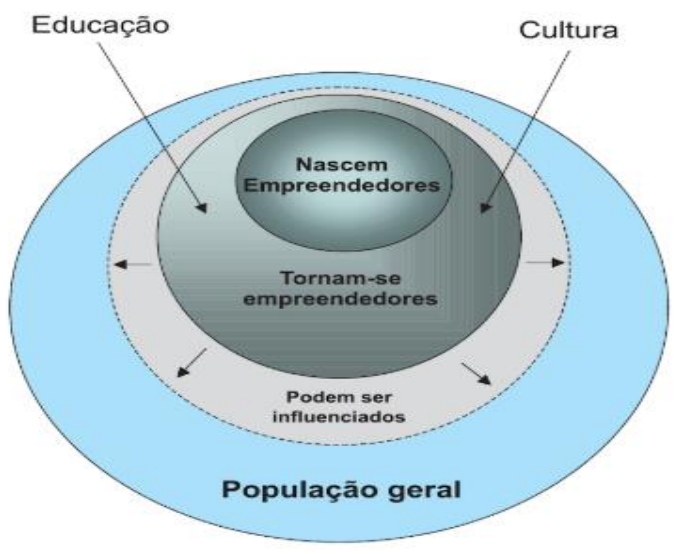

Fonte: Sarkar (2008).

Segundo Schumpeter (2017), muitas vezes, as grandes empresas monopolizam a promoção de inovações, no entanto, boa parcela das inovações surge das mãos de pequenas e novas empresas. Nesse processo, a criatividade não pode ser roteirizada, de modo que, se as grandes empresas suprimirem a oportunidade das pequenas e novas empresas, o processo de inovação não terá resultado positivo.

\section{Microempreendedor Individual}

A Lei Complementar no 123, sancionada em 14 de dezembro de 2006 pelo então Presidente Luís Inácio Lula da Silva, estabelece normas gerais acerca do tratamento destinado às microempresas e empresas de pequeno porte (LEI COMPLEMENTAR no 123, 2006). Em 19 de dezembro de 2008, sancionou-se a Lei Complementar $n^{\circ} 128$, que altera alguns aspectos da Lei Complementar no 123 e cria a figura do microempreendedor individual (PORTAL DO EMPREENDEDOR, 2019).

O principal traço que diferencia a figura do microempreendedor individual dos demais modelos empresariais é a tributação: a apuração e o recolhimento ocorrem por meio de um regime único de arrecadação. O comitê gestor do Simples Nacional é responsável pela revisão de valores, pela apuração e recolhimento de impostos e contribuições. Estas são realizadas mediante documento único de arrecadação. Enquadra-se na condição de microempresa individual a pessoa jurídica que: aufira, em cada ano calendário, receita bruta inferior a $\mathrm{R} \$ 81.000,00$ ou $\mathrm{R} \$ 6.750,00$ por mês; não tenha participação em outra empresa como sócio ou titular; tenha no máximo um empregado contratado que receba o salário mínimo ou piso da categoria (LEI COMPLEMENTAR nº 128, 2008).

Com a LC no 128, passam a constituir direitos dos MEIs: inscrição no CNPJ, sem custos financeiros ou burocráticos; enquadramento automático no Simples Nacional; isentos dos tributos federais - Imposto de Renda (IR), Programa de Integração Social (PIS), Contribuição para o Financiamento da Seguridade Social (Cofins), Imposto sobre Produtos Industrializados (IPI) e Contribuição Social sobre o Lucro Líquido (CSLL) (CORSEUIL; NERI; ULYSSEA, 2014). 
Ao longo dos anos, o conceito de informalidade tem-se modificado, acompanhando a evolução das empresas e modos de trabalho, cada vez mais menos braçal e mais mecânico. Em uma conferência realizada em 1969, a Organização Internacional do Trabalho considerou, pela primeira vez, o termo "informal" e algumas particularidades, entre elas: propriedade familiar de empreendimento, origem e aporte próprio dos recursos, participação em mercados competitivos não regulamentados pelo Estado (CACCIAMALI, 2000).

Em 2002, na 90ª Conferência Internacional do Trabalho, o termo "informalidade" transformou-se em economia informal, com uma gama variada de formas de trabalho em um mundo que não se caracteriza pela homogeneidade (PERES, 2016).

O microempreendedor individual recolhe o imposto mensalmente, obedecendo a uma taxa que acompanha a variação do salário mínimo. Em 2018, os valores variavam de $\mathrm{R} \$ 49,45$ para comércio e indústria e R \$ 53,45 para serviços. Em 2019, o valor de contribuição modificou-se. A taxa mensal para o microempreendedor individual é de $\mathrm{R} \$ 49,90$ ou $\mathrm{R} \$ 50,40$ para comércio e indústria, de acordo com a necessidade de pagar ou não a taxa de ICMS. O valor para a prestação de serviços passou a ser $\mathrm{R} \$ 54,90 \mathrm{e}$ $\mathrm{R} \$ 55,90$ para comércio e serviços ou indústria e serviços juntos (SEBRAE, 2019).

O microempreendedor individual pode se registrar em uma ocupação principal e até 15 ocupações secundárias. No ano de 2019, houve diversas mudanças em relação às ocupações do microempreendedor individual: extinguiram-se vinte e seis atividades e outras cinco sofreram alterações (SEBRAE, 2019).

Quadro 1 - Alteraç̃es nas atividades do microempreendedor individual no ano de 2019.

\begin{tabular}{|l|l|}
\hline Como era & Como é \\
\hline \multirow{2}{*}{$\begin{array}{l}\text { Comerciante independente de peças e } \\
\text { acessórios para motocicletas e motonetas. }\end{array}$} & $\begin{array}{l}\text { Comerciante independente de peças e acessórios novos } \\
\text { para motocicletas e motonetas. }\end{array}$ \\
\cline { 2 - 2 } $\begin{array}{l}\text { Comerciante independente de peças e acessórios usados } \\
\text { para motocicletas e motonetas. }\end{array}$ \\
\hline \multirow{2}{*}{$\begin{array}{l}\text { Proprietário independente de bar e } \\
\text { congêneres. }\end{array}$} & $\begin{array}{l}\text { Proprietário independente de bar e congêneres, sem } \\
\text { entretenimento. }\end{array}$ \\
\cline { 2 - 2 } $\begin{array}{l}\text { Proprietário independente de bar e congêneres, com } \\
\text { entretenimento. }\end{array}$ \\
\hline $\begin{array}{l}\text { Comerciante independente de animais vivos e e } \\
\text { de artigos e alimentos para animais de } \\
\text { estimação. }\end{array}$ & $\begin{array}{l}\text { Comerciante independente de artigos e alimentos para } \\
\text { animais de estimação (pet shop). Não inclui a venda de } \\
\text { medicamentos. }\end{array}$ \\
\hline
\end{tabular}

Fonte: Sebrae (2019).

O microempreendedor individual afetado pela exclusão de atividades precisa alinhar-se ao regime de Microempresa (ME) ou de empresa de pequeno porte. Sendo assim, recolherá os tributos da empresa pela regra do Simples Nacional como microempresa ou empresa de pequeno porte e utilizará o aplicativo Programa Gerador do Documento de Arrecadação do Simples (PGDAS) para calcular e gerar a guia de recolhimento (SEBRAE, 2019).

\section{Estudos correlatos}


Conforme aponta o estudo de Julião, Leone e Neto (2014), na amostra coletada, 61\% dos microempreendedores pertencem ao sexo feminino. Quanto à atividade desempenhada, verifica-se uma predominância do comércio varejista, 77\%, seguido das atividades que envolvem alimentação, $10 \%$.

Souza (2010) relata que, em sua pesquisa, boa parte dos trabalhadores que se formalizou como empreendedor individual enquadra-se na faixa etária entre 31 e 40 anos. Verifica-se, assim, que o mercado informal é ocupado principalmente por trabalhadores de idade mais avançada. Por meio do sistema MEI, esse público está conseguindo sair da informalidade.

Behling et al. (2015) destacaram um percentual expressivo de empresários que atuam com vendas de porta em porta ou como ambulantes, $23,43 \%$. Os que atuam com estabelecimento fixo, $56,62 \%$. A atuação exclusiva pela internet tem baixa representatividade, representa $6,89 \%$ das empresas.

Em relação à escolaridade dos microempreendedores individuais, o estudo aponta um percentual de $65 \%$ de empresários com ensino médio ou técnico completo ou mais, ou seja, a maioria. Uma pequena parte da amostra, $0,5 \%$ não tem instrução formal e $18 \%$ não têm o ensino fundamental completo (ÀS MICRO..., 2017).

\section{Procedimentos metodológicos}

Este trabalho tem o objetivo de analisar as características do perfil e dos negócios dos microempreendedores individuais do município de Campos Novos-SC. De acordo com Beuren (2004), as pesquisas aplicáveis à contabilidade dividem-se em três categorias: quanto aos objetivos, quanto aos procedimentos e quanto à abordagem do problema.

Sob o ponto de vista de sua natureza, o estudo foi estruturado por meio de pesquisa básica. Segundo Gerhardt e Silveira (2009), a pesquisa segmentada segundo essa ótica "objetiva gerar conhecimentos novos, úteis para o avanço da ciência, sem aplicação prática prevista. Envolve verdades e interesses universais".

Quanto à abordagem, a pesquisa se caracteriza como qualitativa. O método qualitativo compreende um conjunto de interpretações que visam descrever e decodificar os componentes de um sistema complexo de significados, tentando traduzir e expressar o sentido dos fenômenos do mundo social (NEVES, 1996). Além de auxiliar nas interpretações, ajudam na análise de informações mais precisas, contribuindo para obter resultados importantes dentro das organizações.

Quanto aos objetivos, a pesquisa classifica-se como bibliográfica. De acordo com Gil (2010), essa pesquisa é desenvolvida com base em material já elaborado, constituído principalmente de livros e artigos científicos. Quanto aos procedimentos, a pesquisa tem caráter documental. Segundo Martins e Theophilo (2007), a pesquisa documental poderá ser uma fonte de dados e informações auxiliares, subsidiando o melhor entendimento de achados e corroborando evidências coletadas por outros instrumentos e fontes. 
A população da pesquisa constitui-se de microempreendedores individuais do município de Campos Novos-SC, cujas empresas constam no site do Portal do microempreendedor e da Receita Federal do Brasil. A amostra classifica-se como intencional. A coleta de dados ocorreu com base em dados secundários, ou seja, nas informações sobre os microempreendedores individuais, referentes ao período de 2014 a 2018.

Os dados foram analisados com base nas informações obtidas e passaram a compor tabelas e gráficos e um relatório descritivo sobre o perfil e os negócios dos microempreendedores individuais do município de Campos Novos-SC.

\section{Resultados e discussão}

A presente pesquisa leva em consideração os aspectos gerais das microempresas individuais da cidade de Campos Novos-SC, do ano de 2014 a 2018. Os dados coletados na Receita Federal e no Portal do Empreendedor embasam os resultados apresentados a seguir. Os resultados podem conter algum viés, e, em alguns casos, conter números divergentes, porque a consulta foi realizada em diferentes fontes.

De acordo com dados os coletados em março de 2018, no Portal do Empreendedor, a Tabela 1 mostra a quantidade de MEIs com sede em Campos Novos-SC, e, em percentagem, seu crescimento ano a ano, de 2014 a 2018.

Tabela 1 - Total de empresas inscritas no programa de microempreendedor individual em Campos Novos-SC, de 2014 a 2018.

\begin{tabular}{c|c|c}
\hline Ano & Total de MEIs & Crescimento \% \\
\hline 2014 & 684 & \\
\hline 2015 & 871 & $27 \%$ \\
\hline 2016 & 1.018 & $17 \%$ \\
\hline 2017 & 1.164 & $14 \%$ \\
\hline 2018 & 1.150 & $-1 \%$ \\
\hline
\end{tabular}

Fonte: Portal do Empreendedor (2019).

$\mathrm{Na}$ Tabela 1, é possível verificar que o número de microempreendedores individuais no município de Campos Novos-SC vem crescendo desde 2014 até 2017, com exceção do ano de 2018, que teve uma pequena queda na quantidade de MEIs.

A Tabela 2 demonstra que, das 1.158 microempresas localizadas na cidade de Campos NovosSC, 632 são comandadas por pessoas do gênero masculino e 526 do gênero feminino, o que representa $55 \%$ e $45 \%$, respectivamente. Os resultados corroboram o estudo de Julião, Leone e Neto (2014), segundo o qual, $61 \%$ dos microempreendedores pertencem ao sexo feminino. 
Tabela 2 - Total de empresas inscritas no programa de microempreendedor individual em Campos Novos-SC, por sexo.

\begin{tabular}{c|c|c}
\hline Total de MEIs & Masculino & Feminino \\
\hline 1.158 & 632 & 526 \\
\hline
\end{tabular}

Fonte: Portal do Empreendedor (2019).

O Quadro 2 apresenta as cinco principais atividades dos microempreendedores individuais do município de Campos Novos-SC. Verifica-se que o CNAE com mais inscrições corresponde a "obras de alvenaria," e aponta o gênero mais significativo nas cinco atividades listadas a seguir.

Quadro 2 - Cinco principais atividades exercidas pelos microempreendedores da cidade de Campos Novos-SC, por sexo.

\begin{tabular}{|c|c|c|c|c|}
\hline CNAE & Descrição da atividade & $\begin{array}{c}\text { Total de } \\
\text { inscritos }\end{array}$ & Masculino & Feminino \\
\hline 4399103 & Obras de alvenaria & 127 & 122 & 5 \\
\hline 9602501 & Cabeleireiros & 109 & 28 & 81 \\
\hline 4781400 & Comércio varejista de artigos de vestuário e \\
acessórios & 102 & 21 & 81 \\
\hline 5611202 & $\begin{array}{c}\text { Bares e outros estabelecimentos especializados em } \\
\text { servir bebidas }\end{array}$ & 76 & 39 & 37 \\
\hline 7319002 & Promoção de vendas & 32 & 17 & 15 \\
\hline
\end{tabular}

Fonte: Portal do Empreendedor (2019).

As informações apontam uma quantidade maior de microempreendedor individual do gênero masculino. As atividades principais do município são obras de alvenaria, gestão de bares e outros estabelecimentos e vendas, portanto, são desenvolvidas preponderantemente por pessoas do gênero masculino. Entre as atividades exercidas por pessoas do sexo feminino, destacam-se cabeleireiros e comércio atacadista de artigos de vestuário e acessórios. Os resultados mantêm uma relação com o estudo de Julião, Leone e Neto (2014), quando se verifica uma predominância do comércio varejista, em torno de $77 \%$, entre pessoas do sexo feminino.

De acordo com os dados da Receita Federal, 2016 foi o ano com a maior média de receita bruta declarada pelas microempresas na cidade de Campos Novos-SC. Ademais, de 2014 a 2016, a média da receita bruta estava em crescimento, sendo que entre 2016 e 2017 houve uma pequena queda nesse faturamento. É o que mostra a Tabela 3. 
Tabela 3 - Média de receita bruta declarada.

\begin{tabular}{c|c}
\hline Ano & Média de receita bruta declarada \\
\hline 2014 & $\mathrm{R} \$ 23.785,30$ \\
\hline 2015 & $\mathrm{R} \$ 25.171,05$ \\
\hline 2016 & $\mathrm{R} \$ 25.172,37$ \\
\hline 2017 & $\mathrm{R} \$ 25.146,77$ \\
\hline 2018 & $\mathrm{R} \$ 6.058,62$ \\
\hline
\end{tabular}

Fonte: Receita Federal (2019).

A Tabela 4 demonstra a constituição de MEIs, o enquadramento e desenquadramento, bem como a exclusão de ofício, de 2014 a 2017. O ano de 2017 teve uma quantidade maior de constituição de MEIs e 2018 foi o que somou o maior número de exclusões de ofício, além de ser o segundo em desenquadramentos do SIMEI.

Verifica-se que a quantidade de exclusão de ofício evoluiu em 2018. Isso ocorre usualmente quando os microempreendedores individuais deixam de atender quaisquer das condições impostas à condição de microempreendedor individual, como, por exemplo, ultrapassar o limite de faturamento anual, ou seja, $\mathrm{R} \$ 81.000,00$.

Por outro lado, o desenquadramento por opção pode ser realizado a qualquer tempo, e começa a produzir efeitos a partir de $1^{\circ}$ de janeiro do ano-calendário subsequente, salvo se a comunicação for feita no mês de janeiro. Nesse caso, os efeitos do desenquadramento ocorrerão nesse mesmo ano-calendário.

O desenquadramento do MEI não implica exclusão do Simples Nacional. O contribuinte desenquadrado como MEI passará, a partir da data de início dos efeitos do desenquadramento, a recolher os tributos devidos pela regra geral do Simples Nacional, como microempresa ou empresa de pequeno porte, exceto se incorrer em alguma das situações previstas para a exclusão do Simples Nacional.

Tabela 4 - Constituição, enquadramento, desenquadramento e exclusão de ofício dos MEIs de Campos Novos-SC, de 2014 a 2018.

\begin{tabular}{c|c|c|c|c}
\hline Ano & Constituição & Enquadramento & Desenquadramento & Exclusão de ofício \\
\hline 2014 & 187 & 4 & 5 & 49 \\
\hline 2015 & 231 & 13 & 13 & 49 \\
\hline 2016 & 222 & 7 & 8 & 67 \\
\hline 2017 & 262 & 7 & 28 & 94 \\
\hline 2018 & 183 & 4 & 18 & 231 \\
\hline
\end{tabular}

Fonte: Receita Federal (2019).

A Tabela 5 mostra os índices de adimplência e inadimplência dos microempreendedores da cidade de Campos Novos-SC no ano de 2018. A maior adimplência acontece nos meses de dezembro e fevereiro. A inadimplência, em janeiro e abril. 
Tabela 5 - Adimplência e inadimplência das microempresas da cidade de Campos Novos/SC, em 2018.

\begin{tabular}{c|c|c}
\hline Mês & Adimplência & Inadimplência \\
\hline Janeiro & $47,16 \%$ & $52,84 \%$ \\
\hline Fevereiro & $61,57 \%$ & $38,43 \%$ \\
\hline Março & $58,83 \%$ & $41,17 \%$ \\
\hline Abril & $53,77 \%$ & $46,23 \%$ \\
\hline Maio & $57,41 \%$ & $42,59 \%$ \\
\hline Junho & $55,63 \%$ & $44,37 \%$ \\
\hline Julho & $57,52 \%$ & $42,48 \%$ \\
\hline Agosto & $60,36 \%$ & $39,64 \%$ \\
\hline Setembro & $56,76 \%$ & $43,24 \%$ \\
\hline Outubro & $57,23 \%$ & $42,77 \%$ \\
\hline Novembro & $60,14 \%$ & $39,86 \%$ \\
\hline Dezembro & $66,09 \%$ & $33,91 \%$ \\
\hline Fon
\end{tabular}

Fonte: Receita Federal (2019).

No município em estudo, o índice de adimplência é superior ao de inadimplência. Aos microempreendedores em inadimplência são impostas algumas obrigações e restrições. O MEI nessa condição não terá direito à cobertura previdenciária até regularizar os débitos mensais. A dívida é exclusivamente previdenciária, mas a Previdência Social não realiza parcelamentos dos recolhimentos em atraso. O Simples Nacional também não parcela os débitos do MEI. Esse parcelamento é feito apenas para as microempresas e para empresas de pequeno porte, desde que tenham dívidas com valor acima de $\mathrm{R} \$ 600,00$, visto que a parcela mínima é de $\mathrm{R} \$ 300,00$.

Para o MEI que desejar permanecer com a empresa aberta, a recomendação é recolher os atrasados de uma só vez. Caso isso não seja possível, poderá pagar o mês atual mais alguns dos boletos atrasados até quitar todo o débito. Nesse caso, é necessário verificar no boleto a data limite antes de ir ao banco ou à casa lotérica efetuar o pagamento. Se o boleto estiver vencido, o MEI precisará imprimir outro para atualizar a data do pagamento bem como o valor. É importante verificar na Previdência Social sobre o retorno à cobertura social e o cumprimento da carência para solicitar os benefícios a que tem direito.

Para o MEI que desejar encerrar a empresa a recomendação é dar baixa no Portal do Empreendedor o mais rápido possível, para que não sejam gerados novos boletos. A dívida dos boletos gerados permanecerá em aberto no sistema e esses recolhimentos poderão impedir a concessão de algum benefício previdenciário no futuro, visto que não será contabilizada a contribuição mensal dele.

Outra consequência da inadimplência anual é o envio da declaração. A partir do ano subsequente à formalização, os boletos mensais poderão ser gerados somente após o envio das informações da Declaração Anual de Faturamento (DASN/SIMEI). Para cada ano calendário, é necessário realizar uma declaração, sempre no período de janeiro a maio do ano seguinte. $\mathrm{O}$ valor máximo de faturamento anual para o MEI permanecer nessa condição é $\mathrm{R} \$ 60.000,00$, ou proporcional, até $\mathrm{R} \$ 5.000,00$ por mês. Caso não haja nenhuma movimentação na empresa, a declaração deverá ser feita informando o valor $R \$ 0,00$.

Caso deixe de enviar a declaração dentro do prazo, o MEI não conseguirá gerar os boletos do ano, ficando inadimplente com os boletos mensais DAS e irregular perante a Receita Federal. Essa 
declaração deve ser feita independentemente de o MEI permanecer com o CNPJ ou dar baixa. Para dar baixa, é preciso enviar também a declaração de Situação Especial "Extinção".

Após o período para envio da declaração, a multa gerada automaticamente pelo sistema fica no valor de $\mathrm{R} \$ 25,00$ até o dia do vencimento. Por isso, a recomendação é efetuar o pagamento para evitar pendências no futuro. Essa multa passa a ser de $\mathrm{R} \$ 50,00$ após o vencimento informado no próprio documento.

O MEI não conseguirá obter Certidões Negativas de Débito na Receita Federal enquanto não quitar as multas (s) geradas pela entrega da declaração fora do prazo. Geralmente, essas certidões são exigidas quando uma pessoa adquire um imóvel, realiza algum procedimento com o Governo Federal, solicita um financiamento etc.. O MEI deve estar ciente de que a RFB continuará cobrando a dívida, mesmo que esta não esteja inscrita em dívida ativa.

\section{Considerações finais}

A figura do microempreendedor trouxe modernização ao processo de regularização de trabalhadores de pequeno porte no que tange às seguridades previdenciária e tributária.

De modo geral, as características do perfil do microempreendedor de Campos Novos-SC se mantêm nos anos de 2014 a 2018. Quanto ao gênero, 55\% dos microempreendedores são homens, e a principal atividade exercida no município por estes são obras de alvenaria. De acordo com o estudo, nas cinco atividades mais inscritas por CNAE, o gênero masculino predomina sobre o gênero feminino. Porém, as atividades listadas são exercidas predominantemente por homens. Nas atividades em que predomina a figura feminina, as mulheres são mais representativas, o que demonstra homogeneidade nesse aspecto.

A inscrição de empresas no programa do microempreendedor individual apresentou pequena variação ano a ano, destacando-se uma quase imperceptível diminuição entre 2017 e 2018.

Com isso, surge uma lacuna na pesquisa, pois a diminuição das inscrições no programa demonstra que ou mais empreendedores estão migrando para o programa de micro e pequenas empresas ou apenas desistindo de regularizar sua atividade. Verifica-se tal condição diante das 231 exclusões de ofício no ano de 2018. Com o desenquadramento, pode haver desistência da atividade ou mesmo migração para o Simples Nacional.

Assim sendo, percebe-se que tal grau de inadimplência decorre de uma decrescente desde janeiro, com pequenas oscilações. Isso demonstra que a maioria dos microempreendedores do município tem conhecimento das suas obrigações.

Desse modo, para uma pesquisa futura, a sugestão é que o estudo seja realizado em outros municípios da mesorregião com a aplicação de um questionário in loco, com vistas à comparação de informações e (possível) identificação de novas características entre os microempreendedores individuais. 


\section{Referências}

ÀS MICRO, Serviço Brasileiro de Apoio; EMPRESAS-SEBRAE, Pequenas. Perfil do Microempreendedor Individual 2017. [S. l.], 2017. Disponível em: http://ambientedigital. sebraers. com. br/Download/Arquivos/Perfil_MEI_2013.pdf, 2013. Acesso em: 20 mar. 2019.

BEUREN, Ilse Maria. Como elaborar trabalhos monográficos em contabilidade: teoria e prática. 3. ed. São Paulo: Atlas 2004.

BEHLING, Gustavo et al. Microempreendedor individual catarinense: uma análise descritiva do perfil dos empreendedores individuais em Santa Catarina. NAVUS-Revista de Gestão e Tecnologia, Florianópolis, $\quad$ v. 5, n. 1, p. 65-78, 2015. Disponível el http://navus.sc.senac.br/index.php/navus/article/view/217. Acesso em: 22 mar. 2019.

BRASIL. Lei Complementar n. 128, de 14 de dezembro de 2006. Dispõe do Estatuto Nacional da Microempresa e da Empresa de Pequeno Porte. Diário Oficial da União: Brasília, DF, 2006. Disponível em: http://www.planalto.gov.br/ccivil 03/LEIS/LCP/Lcp123.htm. Acesso em 12 fev. 2019.

CACCIAMALI, Maria Cristina. Globalização e processo de Informalidade. Economia e Sociedade. Campinas, p. 153-174, jun. 2000.

CORSEUIL, Carlos Henrique L.; NERI, Marcelo Côrtes; ULYSSEA, Gabriel. Uma análise exploratória dos efeitos da política de formalização dos microempreendedores individuais. Texto para Discussão, Instituto de Pesquisa Econômica Aplicada (IPEA), Brasília, DF, 2014.

CUSTÓDIO, Telma Padilha. A importância do empreendedorismo como estratégia de negócio. 2011. Monografia (Graduação em Administração) - Centro Universitário Católico Salesiano AuxiliumUNISALESIANO, Lins-SP, 2011.

DORNELAS, José Carlos Assis. Empreendedorismo: transformando ideias em negócios. 2. ed. rev. atual. Rio de Janeiro: Campus, 2001.

FECOMERCIO/SP. Lei do MEI completa dez anos como importante fonte de geração de emprego e renda. São Paulo, 6 nov. 2018. Disponível em: http://www.fecomercio.com.br/noticia/lei-do-meicompleta-dez-anos-como-importante-fonte-de-geracao-de-emprego-e-renda. Acesso em: 22 mar. 2019.

GERHARDT, Tatiana Engel; SILVEIRA, Denise Tolfo (Org.). Métodos de Pesquisas. Porto Alegre: UFRGS, 2009. Disponível em: http://www.ufrgs.br/cursopgdr/downloadsSerie/derad005.pdf. Acesso em: 1 maio 2016.

GIL, Antônio Carlos. Como elaborar projetos de pesquisa. 5. ed. São Paulo: Atlas, 2010.

JULIÃO, Flávio; LEONE, Rodrigo José Guerra; NETO, Alípio Ramos Veiga. Fatores determinantes da satisfação de usuários do Programa Microempreendedor Individual. Teoria e Prática em Administração (TPA), Paraíba, v. 4, n. 1, p. 156-179, 2014. Disponível em: http://www.spell.org.br/documentos/ver/31150/fatores-determinantes-da-satisfacao-de-suarios-doprograma-microempreendedor-individual. Acesso em: 22 mar. 2019.

MARTINS, Gilberto de Andrade; THEÓPHILO, Carlos Renato. Metodologia da investigação científica para ciências sociais aplicadas. São Paulo: Atlas, 2007.

MAXIMIANO, Antonio Cesar Amaru. Administração para empreendedores: fundamentos da criação e da gestão de novos negócios. 2. ed. São Paulo: Pearson

Prentice Hall, 2011. 
NEVES, José Luis. Pesquisa qualitativa: características, usos e possibilidades. Caderno de pesquisas em administração, São Paulo, v. 1, n. 3, p. 1-5, 1996.

PERES, Thiago Brandão. Informalidade: um conceito em busca de uma teoria. Revista da ABET, [s. l.], v. 14, n. 2, 2016. Disponível em: http://www.periodicos.ufpb.br/index.php/abet/article/view/27956. Acesso em: 20 fev. 2019.

PORTAL DO EMPREENDEDOR. Entenda, o que é? $[S$. l.], 2019. Disponível em: http://www.portaldoempreendedor.gov.br/. Acesso em: 20 mar. 2019.

SARKAR, Soumodip. O empreendedor inovador: faça diferente e conquiste seu espaço no mercado. Rio de Janeiro: Elsevier, 2008.

SEBRAE. Mudanças para o MEI: atividades, declaração anual e contratação. [S. l.], 2019. Disponível em: http://www.sebrae.com.br/sites/PortalSebrae/artigos/mudancas-nas-atividades permitidas-para-omicroempreendedor individual,c347ddf358658610VgnVCM1000004c00210aRCRD. Acesso em: $22 \mathrm{fev}$. $\underline{2019 .}$

SCHUMPETER, Joseph A. Capitalismo, socialismo e democracia. São Paulo: SciELO-Editora UNESP, 2017.

SOUZA, Dayanne Marlene. Os principais benefícios proporcionados ao trabalhador informal para formalização através do Microempreendedor Individual. Monografia (Graduação em Ciências Contábeis) - Universidade Federal de Santa Catarina - UFSC, 2010. Disponível em: https://repositorio.ufsc.br/xmlui/bitstream/handle/123456789/127035/Contabeis294059.pdf?sequence =1\&isAllowed $=y$. Acesso em: 20 fev. 2019.

ULYSSEA, Gabriel. Informalidade no mercado de trabalho brasileiro: uma resenha da literatura. Rev. Econ. Polit., São Paulo, v. 26, n. 4 out./dez. $2006 . \quad$ Disponível em: http://www.scielo.br/scielo.php?script=sci_arttext\&pid=S0101-31572006000400008. Acesso em: 22 fev. 2019. 